\title{
Predation and avoidance behavior of the pea aphid Acyrthosiphon pisum confronted with native and invasive lady beetles in Europe
}

\author{
Ayse Gül Ünlü (D) Jördis F. Terlau • Roman Bucher
}

Received: 21 July 2019/ Accepted: 17 January 2020/Published online: 23 January 2020

(C) The Author(s) 2020

\begin{abstract}
Invasive species are a major driver of global biodiversity loss. However, we often lack a mechanistic understanding why some non-native species become invasive. Missing coevolutionary history between invasive predators and native prey can lead to a lack of predator avoidance by native prey and consequently higher consumption rates by invasive predators. We compared predation rates of four native European lady beetle species and the invasive lady beetle species Harmonia axyridis Pallas (Coleoptera: Coccinellidae), using the native pea aphid Acyrthosiphon pisum Harris (Hemiptera: Aphididae) for prey. Here, we also quantified initial dropping of $A$. pisum from host plants. In an additional plant-choice experiment, we tested for aphid avoidance of plants bearing lady beetle cues. Differences in predation were determined by predator body size. Initial dropping of aphids did not differ between the invasive lady beetle species $H$. axyridis and the remaining native
\end{abstract}

A. G. Ünlü $(\bowtie) \cdot$ J. F. Terlau · R. Bucher Philipps-Universität Marburg, Conservation Ecology, Karl-von-Frisch-Str. 8, 35043 Marburg, Germany e-mail: ayse.uenlue@biologie.uni-marburg.de

J. F. Terlau

German Centre for Integrative Biodiversity Research (iDiv) Halle-Jena-Leipzig, Deutscher Platz 5e, 04103 Leipzig, Germany

\section{J. F. Terlau}

Friedrich-Schiller-Universität Jena, Institute of Biodiversity, Dornburger Str. 159, 07743 Jena, Germany lady beetle species. However, A. pisum showed no avoidance behavior towards $H$. axyridis cues, but to cues of the most voracious native species. Thus, relatively large body size and missing chemical cue avoidance by aphids can benefit the invasive $H$. axyridis.

Keywords Predator-prey naïveté · Coevolution · Invasion $\cdot$ Antipredator response $\cdot$ Predator avoidance $\cdot$ Harmonia axyridis Pallas (Coleoptera: Coccinellidae)

\section{Introduction}

Novel species interactions can play a pervasive role in the invasion success of non-native species and their ecological impact (Carthey and Banks 2014). Several evolutionary and ecological hypotheses focus on novel species interactions (Hufbauer and Torchin 2007). The evolution of increased competitive ability (EICA) hypothesis, for example, implies that novel species might benefit from the absence of native top and intraguild predators, reducing the impact on population growth through reduced predation. Thus, the reduced resource allocation to antipredator response in the novel species, leads to a higher competitive ability and consequently to higher fitness (Blossey and Notzold 1995). Besides the absence of predators, 
missing predator recognition of prey can result in similar consequences for predators: According to the prey-naïveté hypothesis, a lack of coevolutionary history between native prey and novel predator results in missing species recognition and ineffective antipredator response of native prey, leading to higher consumption rates of the novel predator (Cox and Lima 2006; Sih et al. 2010). While the majority of studies focus on prey naïveté of vertebrates and aquatic organisms (Cox and Lima 2006), there is little scientific understanding of predator-prey-naïveté in arthropods.

Interspecific communication is crucial for species recognition in trophic interactions (Lima and Dill 1990). The assessment of predation risk by prey is mediated by general and/or specific cues (Sih et al. 2010). In arthropods, chemical cues (e.g. cuticular waxes; Dixon 2000; Pasteels 2007) are known to mediate mutualistic and antagonistic interactions (Lang and Menzel 2011; Bucher et al. 2014; Dixon 2000; Mestre et al. 2014). Since predator-specific chemical traces are left by predators on feeding sites, prey species evolved mechanisms to assess and avoid chemical cues of syntopic predators to reduce risk of predation (Ninkovic et al. 2013; Bucher et al. 2015a). Hence, native prey can suffer from heavy predation after the introduction of a non-native species (Sih et al. 2010). However, chemical cue similarity between native and non-native predators could enhance prey recognition and subsequently mediate invasion success (Sih et al. 2010).

Aphids (Hemiptera: Aphididae) have evolved several survival strategies to escape predation, such as kicking, walking away, dropping from the plant and releasing an alarm pheromone to warn neighboring aphids (Villagra et al. 2002; Francke et al. 2008). In addition, aphids can respond to predator presence with the production of winged offspring, allowing for future dispersal (Lees 1966; Weisser et al. 1999). The pea aphid Acyrthosiphon pisum Harris (Hemiptera: Aphididae) is originally a Palearctic species, which started spreading in the late nineteenth-century and is now globally distributed (Thomas 1878). The species A. pisum consists of numerous sympatric populations, characterized by genetic or phenotypic divergence and differences in host plant adaptation in its local range (Peccoud et al. 2009; Peccoud and Simon 2010). Aphids are an essential food resource for several lady beetle species (Coleoptera: Coccinellidae) (Gordon
1985; Obrycki and Kring 1998), e.g. the Asian multicolored lady beetle Harmonia axyridis Pallas (Coleoptera: Coccinellidae) is a voracious predator of aphids in agricultural landscapes (Hukusima and Ohwaki 1972). From 1995, H. axyridis was introduced as a biocontrol agent in Central Europe (Brown et al. 2008). The period of spread and establishment of Harmonia axyridis in most parts of Central Europe ranged from 2002 to 2007 (Klausnitzer 2002; Brown et al. 2008). Within two decades, this beneficial, nonnative species became a successful invader with high dispersal and establishment abilities and wide food spectrum. The spread of $H$. axyridis is associated with the decline of native lady beetles in Europe (Majerus et al. 2006; Van Lenteren et al. 2008; Roy et al. 2012) and North America (Brown and Miller 1998; Alyokhin and Sewell 2004).

We applied a multi-species approach to compare the strength of predator-prey interactions between the invasive Asian lady beetle species Harmonia axyridis, four native European lady beetle species, Coccinella septempunctata Linnaeus, Adalia bipunctata Linnaeus, Propylea quatuordecimpunctata Linnaeus, and Hippodamia variegata Goeze (Coleoptera: Coccinellidae), using the native pea aphid Acyrthosiphon pisum for prey. We expected (1) higher aphid predation of $H$. axyridis compared to the native lady beetle species and (2) higher dropping rates if confronted with native lady beetle species compared to $H$. axyridis. In addition, we expected (3) weaker response of $A$. pisum confronted with $H$. axyridis cues, compared to cues of native lady beetle species. This plant choice experiment allowed us to evaluate the role of chemical cues mediating avoidance behavior towards native and invasive lady beetles.

\section{Materials and methods}

\section{Study species}

Broad bean plants Vicia faba Linnaeus (Fabales: Fabaceae) (variety Sutton dwarf; Kings Seeds Essex, UK) were planted weekly in plastic trays $(56.5 \times 41.5 \times 8.5 \mathrm{~cm})$ under room conditions. After seedling emergence, seedlings were potted in groups of six to eight in open plastic containers $(18 \times 13.5 \times 6.5 \mathrm{~cm})$ in a climate chamber $\left(20 \pm 1{ }^{\circ} \mathrm{C}, 65 \%\right.$ relative humidity and $16 \mathrm{~h} \mathrm{~L}: 8 \mathrm{~h}$ 
D photoperiod). Pea aphids (Acyrthosiphon pisum) were obtained from a laboratory colony of the Julius Kühn-Institut (Braunschweig, Germany), which were maintained in the laboratory for more than 10 years. To test for prey naïveté, we chose an unexperienced laboratory aphid population. Here, the aphid laboratory colony was established, when spread and establishment of $H$. axyridis started in Central Europe (see above, Brown et al. 2008). Consequently, this aphid colony has not experienced high $H$. axyridis densities in the field.

Aphids were maintained on single (2-3 weeks old) broad bean plants (see above), which were transplanted from plastic containers to plastic cups $(11.5 \times 12.5 \mathrm{~cm})$ and subsequently covered with gauze for aeration in a climate chamber $\left(20 \pm 1{ }^{\circ} \mathrm{C}\right.$, $65 \%$ relative humidity and $16 \mathrm{~h} \mathrm{L:} 8 \mathrm{~h} \mathrm{D}$ photoperiod). Aphids were transferred weekly to new plants to guarantee fresh food supply. Lady beetles were collected in agricultural and semi-natural habitats from March to August 2017 in Germany, Switzerland and France. Based on observations in field and laboratory (mating activity), the majority of beetles used for the experiments were sexually mature. Individuals of all species, used for the experiments were short-term stored (less than 30 days) under low temperatures $\left(8 \pm 1{ }^{\circ} \mathrm{C}\right)$ in plastic collecting tubes $(5.3 \times 10.0 \mathrm{~cm}$ and $3.6 \times 8.3 \mathrm{~cm})$ with a water containing microtube for moisture supply, until sufficient numbers of individuals were collected for the respective experiments. Here, cold storage is not expected to have adverse effects on lady beetle behavior in the experiments, due to the short storage period and appropriate storage conditions (Watanabe 2002; Labrie et al. 2008; Ruan et al. 2012). In addition, lady beetles had an acclimatization time of at least $48 \mathrm{~h}$ prior to start of the experiments.

Due to an insufficient number of wild $A$. bipunctata individuals found $(\mathrm{N}=10)$, larvae and adults were purchased (Sautter \& Stepper GmbH and BioInsecte). At least $48 \mathrm{~h}$ prior to the experiments, lady beetle adults were placed into Petri dishes $(9.4 \times 1.6 \mathrm{~cm})$ and fed ad libitum with pea aphids on single Vicia faba leaves. Lady beetles were maintained under constant conditions $\left(20{ }^{\circ} \mathrm{C}, 65 \%\right.$ relative humidity and $16 \mathrm{~h} \mathrm{~L}$ : $8 \mathrm{~h}$ D photoperiod). Plants, lady beetles and aphids were randomly selected for the experiments. All experiments were conducted in microcosms under daylight conditions (natural and supportively artificial lighting) at $24.2 \pm 0.8{ }^{\circ} \mathrm{C}$ in the laboratory from May to September 2017.

Experimental setup and procedure

\section{Predation and dropping experiments}

Lady beetles were starved for $24 \mathrm{~h}$ and singly kept in Petri dishes $(3.5 \times 1.0 \mathrm{~cm})$. Prior to the experiments, body width (widest horizontal distance between the two closed elytra) of each beetle used for the experiment, was measured under the microscope. Body width is easy to measure on living beetles and used as a proxy for body size (Eberhard 1982). Species-specific body sizes were obtained, to account for size-related metabolic constraints of food consumption (Brose et al. 2008).

Single 2-3-week-old broad bean plants were trimmed to two leaves for standardization and potted into a glass vial $(2.2 \times 4.5 \mathrm{~cm})$. Fluon ${ }^{\circledR}$ (Polytetrafluoroethylene dispersion) was applied on the stem and the vial, to prevent dropped aphids from climbing back on the plant. Petri dishes $(9.4 \times 1.6 \mathrm{~cm})$ were treated with Fluon ${ }^{\circledR}$ on the inner walls and subsequently used as ground cover for the experiments. Thirty 2nd-3rd instar aphids were placed on each plant with a brush. Adult aphids were not used in the experiment, due to the possibility of offspring production, increasing the total amount of aphids in our experiments. After an acclimation time of 30 min for aphids to settle on the plant, a single lady beetle adult was added at the top of the plant. To prevent lady beetles from escaping, a plastic cup was placed over each plant and petri-dish. Predation was assessed after 0.25, 0.5, 1, 2, 3, 4, 5 and $6 \mathrm{~h}$, quantifying the remaining number of aphids in each microcosm. Twenty-three replicates were conducted for each lady beetle species in the predation experiments, divided into ten experimental blocks.

Initial dropping was assessed $15 \mathrm{~min}$ after placing lady beetles on the plants, counting aphids on the ground of each Petri dish. We assessed aphid dropping only at the beginning of the experiment, since dropped and consumed aphids could not be subsequently distinguished. We excluded microcosms from the initial dropping analysis, when beetles were observed to be on the cup or ground after $15 \mathrm{~min}$, since aphid consumption by beetles on the ground could have reduced the number of aphids dropped. Thus, the number of replicates differed between the predation 
and dropping experiments (Predation experiment: $H$. axyridis $\mathrm{N}=21, C$. septempunctata $\mathrm{N}=20, A$. bipunctata $\mathrm{N}=20, \quad P$. quatuordecimpunctata $\mathrm{N}=23$, and $H$. variegata $\mathrm{N}=21$; Dropping experiment: $H$. axyridis $\mathrm{N}=16, C$. septempunctata $\mathrm{N}=11$, A. bipunctata $\mathrm{N}=17, P$. quatuordecimpunctata $\mathrm{N}=15$, and $H$. variegata $\mathrm{N}=10$ ).

\section{Cue avoidance experiments}

Single standardized broad bean plants (see above) were placed into a petri dish, the plant roots were subsequently covered with soil and the ground was than leveled and compacted. Three lady beetles of the same species were placed on single treatment plants. During $24 \mathrm{~h}$, lady beetles were allowed to walk on the broad bean plants to deposit their chemical cues (e.g. cuticular hydrocarbons). Control and treatment plants were subsequently covered with perforated plastic cups $(9.5 \times 10.5 \mathrm{~cm})$.

After $24 \mathrm{~h}$ lady beetles were removed from the treatment plants. A single treatment and a control plant were positioned opposite each other in a terrarium $(23.0 \times 15.3 \times 16.5 \mathrm{~cm})$ and the remaining bare ground around the petri-dishes was covered with soil (see Bucher et al. 2015b). Prior to the start of the experiments 30 aphids (adult and fourth instars) were placed with a brush into a small Petri dish $(3.5 \times 1.0 \mathrm{~cm})$. Aphids were subsequently released in the center of the terrarium on neutral ground. Terraria were covered with perforated cling film to prevent aphids from leaving. The number of aphids on treatment and control plant were quantified after 0.5 , 1, 1.5, 2, 3, 4 and $6 \mathrm{~h}$. The position of treatments in terraria and cups were randomized prior to the experiments, to account for potential position-related confounding factors. Twenty replicates per lady beetle species were conducted, divided into ten experimental blocks.

\section{Statistical analysis}

To test the effect of lady beetle species on aphid predation over time, we used a Generalized Linear Mixed Model (GLMM, lme4 package, Bates et al. 2015) with a poisson error distribution. The fixed effects included species and time and the random effects experimental unit (i.e. repeated measurements) and observation-level random effect (OLRE), accounting for overdispersion, were added to the model. We obtained statistical parameters for the fixed effects via ANOVA ( $\chi^{2}$ test) from the R package 'car' (Fox and Weisberg 2019). To test for differences between aphid predation of lady beetle species we used a Tukey's contrast test for comparison of means with a Bonferroni correction to account for familywise error rates, by using the glht function from the multcomp package (Hothorn et al. 2008).

Differences of predation rate after $6 \mathrm{~h}$ (last time point) and body width were respectively analyzed with a Games-Howell post hoc test, following a Welch's ANOVA (F test) accounting for variance inhomogeneity.

To test the effect of beetle body width on predation after $6 \mathrm{~h}$ (last time point), we used a Generalized Linear Model (GLM) with a quasi-poisson distribution (accounting for overdispersion). Body width and species were included as fixed effects in the model. Statistical parameters for the fixed effects were obtained via ANOVA ( $\chi^{2}$ test).

In the dropping experiment we tested the effect of lady beetle species on aphids dropped, using a GLM with a quasi-binomial error distribution (accounting for overdispersion). Aphid counts entered the model as proportions (aphids on plant vs. dropped) and species was included as fixed effect. We obtained statistical parameters for the effect of species via ANOVA $\left(\chi^{2}\right.$ test). Multiple comparisons of means were achieved by using Tukey's contrasts method, with a Bonferroni correction.

In the cue avoidance experiment, aphid counts were analyzed as proportions (aphids on control plant vs. treatment plant). We only considered aphids that made a distinct choice of the control or the treatment plant. Therefore, aphids on the ground and terrarium wall were excluded from the analysis. We used a GLMM with a binomial distribution to see the effects of species and time on aphid plant choice. We included species and time as fixed effects and experimental unit and OLRE (accounting for overdispersion) entered the model as random effects. We obtained statistical parameters for the fixed effects via ANOVA $\left(\chi^{2}\right.$ test). We subsequently tested for equality of proportions of aphids on control vs. treatment plants, by applying a GLMM with binomial error distribution. Our fixed effects included species and as random effects we added experimental unit (i.e. repeated measurements) and OLRE (accounting for overdispersion) to the model. 
Statistical analyses were performed with the statistical software R, Version 3.4.0 (R Development Core Team 2017).

\section{Results}

Predation and dropping experiment

Species significantly affected predation rate over time (GLMM, $\chi^{2}=23.33, d f=4, P<0.01$ ). The number of aphids consumed differed between ladybeetle species; H. axyridis and C. septempunctata consumed higher numbers of $A$. pisum than $H$. variegata and $P$. quatuordecimpunctata over a 6-h feeding period (Tukey's contrast test $P<0.02$, respectively; Fig. 1). Predation rates of $A$. bipunctata did not differ significantly from $H$. axyridis and $C$. septempunctata (Tukey's contrast test $P=0.17$ and 0.10 , respectively; Fig. 1). No differences in predation rates were observed between $C$. septempunctata and $H$. axyridis (Tukey's contrast test $P=1.0$; Fig. 1) as well as between $H$. variegata, $A$. bipunctata and $P$. quatuordecimpunctata (Tukey's contrast test $P>0.8$, respectively; Fig. 1).

If only the last time point of $6 \mathrm{~h}$ was analyzed, predation rates differed between species (Welch's Anova, $\left.\mathrm{F}_{4,47.85}=12.41, P<0.01\right)$. C. septempunctata and $H$. axyridis respectively consumed more aphids than $A$. bipunctata, $H$. variegata or $P$. quatuordecimpunctata after $6 \mathrm{~h}$ (Games-Howell test, $P<0.02$, respectively; Fig. 2). Predation rates between $C$. septempunctata and $H$. axyridis did not differ (Games-Howell test, $P>0.99$; Fig. 2). No differences could be observed between $H$. variegata, A. bipunctata and $P$. quatuordecimpunctata (GamesHowell test, $P>0.50$, respectively; Fig. 2).

Body size of species differed (Welch's Anova, $\left.\mathrm{F}_{4,48.63}=374.67, P<0.01\right) . H$. axyridis and $C$. septempuntata were the largest species used in our experiments (Games-Howell test, $P=0.53$; Fig. 2), compared to the smaller $A$. bipunctata, $P$. quatuordecimpunctata and $H$. variegata (Games-Howell test, $P<0.01$, respectively; Fig. 2). A. bipunctata was larger than $P$. quatuordecimpunctata and $H$. variegata (Games-Howell test, $P<0.02$ respectively; Fig. 2).

The predation rate of beetles can be explained by differences in beetle body size (GLM, $\chi^{2}=5.68$, $d f=1, P<0.02$ ) at the last time point of $6 \mathrm{~h}$. If body size was included in the model, aphid predation rates were no longer explained by lady beetle species identity (GLM, $\chi^{2}=4.76, d f=4, P=0.31$ ).

Initial dropping rate of $A$. pisum varied among ladybeetle species (GLM, $\chi^{2}=16.16, \quad d f=4$, $P<0.01$ ). Significantly lower numbers of aphids dropped after encounters with $P$. quatuordecimpunctata compared to C. septempunctata (Tukey's contrast test $P<0.01$; Fig. 3). Moreover, marginally lower numbers of aphids dropped after encounters with $A$. bipunctata compared to $C$. septempunctata (Tukey's contrast test $P<0.07$; Fig. 3). We observed no further significant differences in aphid dropping rate between the different lady beetle species $(P>0.2$, respectively; Fig. 3).

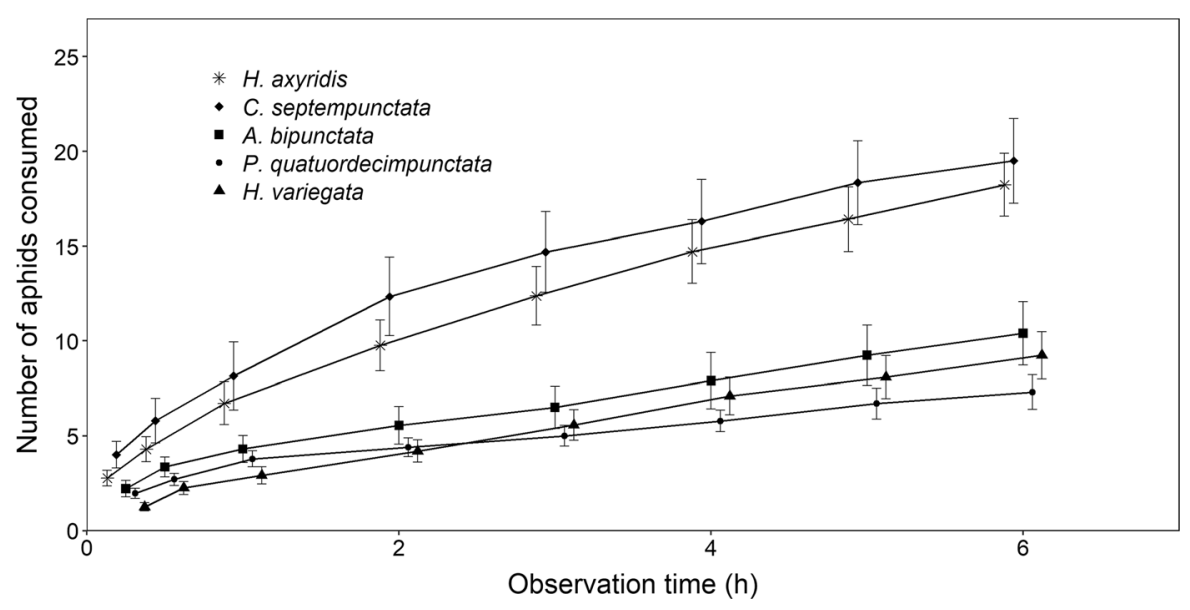

Fig. 1 Number of aphids consumed (mean \pm SE) by the invasive Harmonia axyridis and native lady beetle species (Coccinella septempunctata, Adalia bipunctata, Propylea quatuordecimpunctata, and Hippodamia variegata) over a 6-h feeding period 


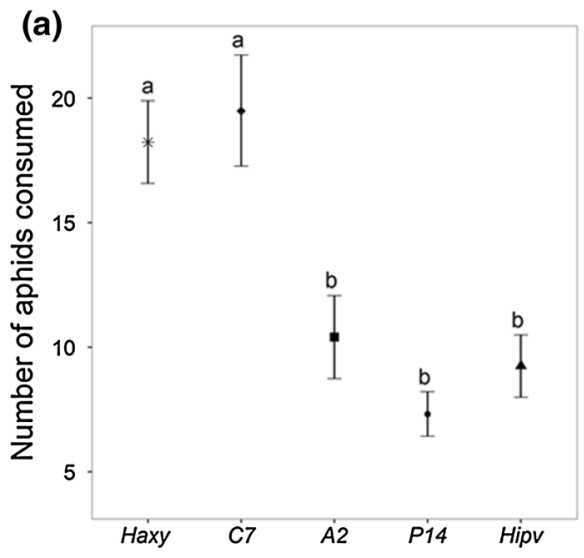

Fig. 2 Number of aphids consumed (mean \pm SE) by the invasive Harmonia axyridis and native lady beetle species (Coccinella septempunctata, Adalia bipunctata, Propylea quatuordecimpunctata, and Hippodamia variegata) after $6 \mathrm{~h}$

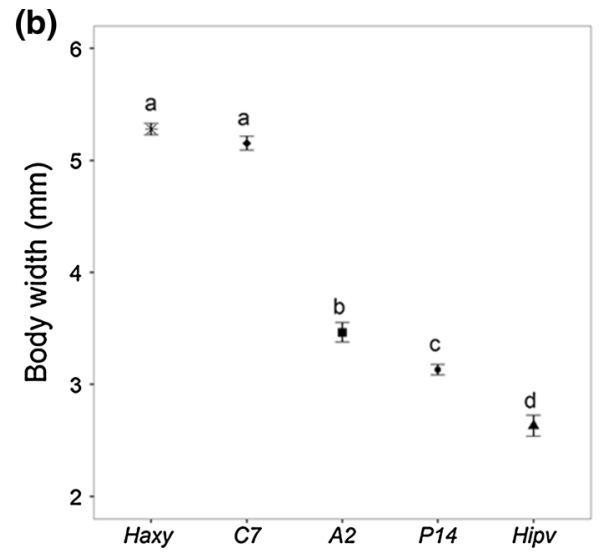

(a). Body width (mean $\pm \mathrm{SE}$ ) in mm of lady beetle species used for the predation and dropping experiments (b). Different lowercase letters indicate statistical differences based on a GamesHowell post hoc test $(P<0.05)$
Fig. 3 Number of aphids dropped (mean $\pm \mathrm{SE}$ ) in the presence of a single lady beetle after $15 \mathrm{~min}$. Differences in dropping rate of lady beetle species were analyzed by Tukey's contrast test for comparison of means $(P<0.05$, same letters do not differ significantly)

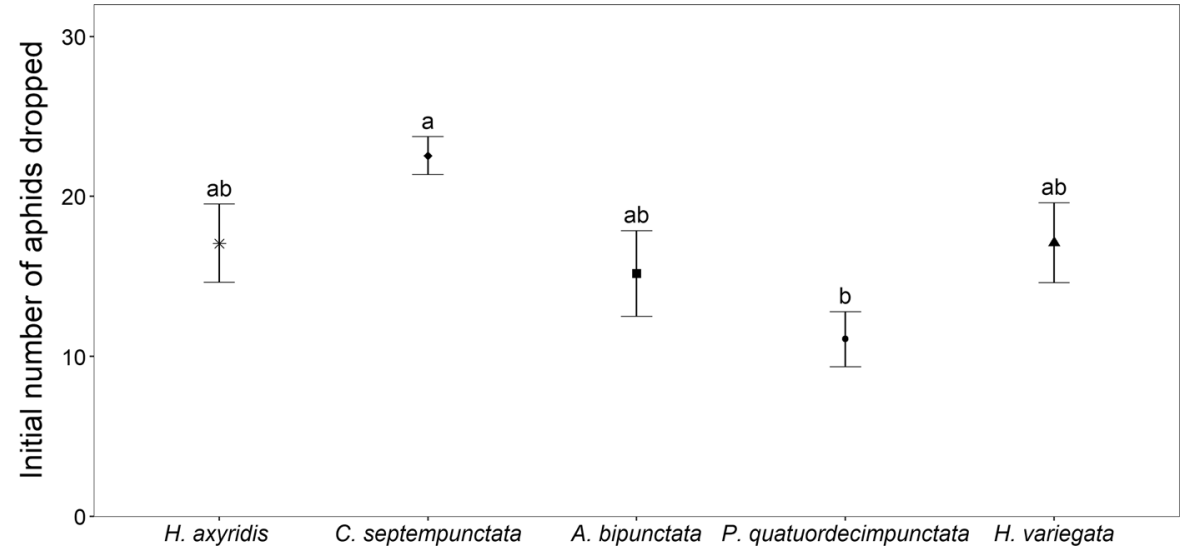

\section{Discussion}

Aphid plant choice was marginally affected by lady beetle species (GLMM, $\chi^{2}=8.18, d f=4, P=0.09$ ) and the effect of time was not significant (GLMM, $\chi^{2}=0.65, d f=1, P=0.42$ ). The test for equality of proportions on control plant vs. treatment plant showed, that aphids avoided plants previously occupied by $C$. septempunctata $\left(\mathrm{z}_{95}=2.00, P<0.05\right)$ (Fig. 4) and showed preference towards the control plant. We observed no avoidance behavior towards cues of H.axyridis $\left(\mathrm{z}_{95}=-0.24, P=0.81\right), \quad A$. bipunctata $\left(\mathrm{z}_{95}=-0.99, P=0.32\right), P$. quatuordecimpunctata $\left(\mathrm{z}_{95}=1.08, P=0.28\right)$ and $H$. variegata $\left(\mathrm{z}_{95}=-1.43, P=0.15\right)$ (Fig. 4).
Aphid predation rates of $H$. axyridis and. C. septempunctata did not differ significantly. A. bipunctata, $H$. variegata and $P$. quatuordecimpunctata respectively consumed significantly fewer aphids than $H$. axyridis or C. septempunctata after $6 \mathrm{~h}$. There were no significant differences in predation rates between $H$. variegata, $P$. quatuordecimpunctata and A. bipunctata. Here, differences in predation rates can be better explained by beetle body size than by species identity.

$C$. septempunctata caused significantly higher dropping rates than $P$. quatuordecimpunctata. Unexpectedly, no differences in aphid dropping could be seen between $H$. axyridis and the remaining species. Predator avoidance was only observed in treatment plants bearing $C$. septempunctata cues, compared to 


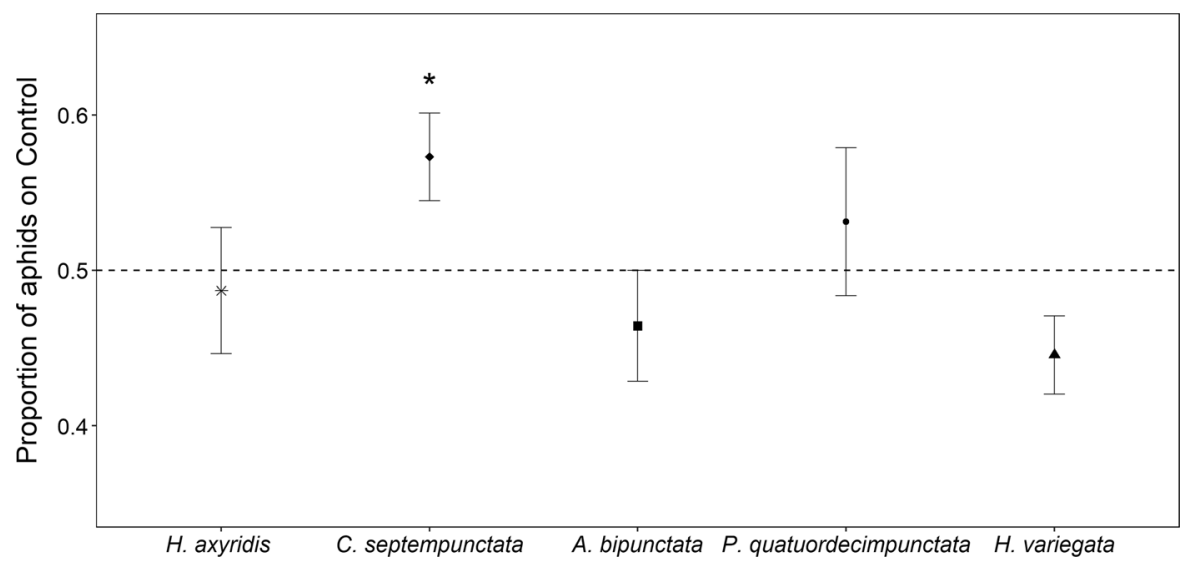

Fig. 4 Proportion of aphids on control plant (mean \pm SE) compared to treatment plant with cues of different lady beetle species. GLMM results indicate avoidance against $C$. septempunctata cues $\left(\mathrm{z}_{95}=2.0, P<0.05\right)$ but not against cues of $H$.

the untreated control plant. A. pisum did not avoid cues of $H$. axyridis and the remaining native species.

Differences in predation among the lady beetles used in our experiments can be explained by beetle body size, being comparable in C. septempunctata and $H$. axyrids, but lower in the remaining native species. No significant differences in predation rates over the whole observation period between A. bipunctata and $H$. axyridis or $C$. septempunctata can be explained by smaller interspecific predation differences at the earlier time points, which increased with time (see Fig. 1). Moreover, intraspecific body size differences (i.e. a few considerably larger individuals) between larger wild individuals and smaller laboratory individuals resulted in higher intraspecific variation of $A$. bipunctata predation rates compared to the other lady beetle species tested. The consumption increases with body size, due to developmental requirements (Hodek 1973). Thus, rather than advantages in predation due to a lack of coevolutionary history, beetle size considerably influences aphid predation. Our results are in line with previous body size related quantitative predation studies of lady beetle species (Finlayson et al. 2010; Mishra et al. 2011). Beetle size and predator efficiency of non-native lady beetle species on shared food resources (Obrycki et al. 1998; Majerus et al. 2006; Roy et al. 2012; Hoki et al. 2014) can be factors contributing to the decline of native lady beetle species.

In the predation experiments, aphids were confronted with physically present predators and therefore axyridis $\left(\mathrm{z}_{95}=-0.24, P=0.81\right)$, A. bipunctata $\left(\mathrm{z}_{95}=-0.99\right.$, $P=0.32), P$. quatuordecimpunctata $\left(\mathrm{z}_{95}=1.08, P=0.28\right)$ and H. variegata $\left(\mathrm{z}_{95}=-1.43, P=0.15\right)$

immediate predation risk, inducing aphid dropping. Dropping behavior is an antipredator response to escape larger predators, like aphidophagous lady beetles, which pose a high predation risk (Evans 1976; Losey and Denno 1998). Contrary to our expectations, aphid dropping rates induced by the presence of the invasive $H$. axyridis are comparable to those of native lady beetle species. Previous studies on coccinellid induced aphid dropping, observed an increase in dropping behavior with increasing body size of the predators (Hoki et al. 2014; Francke et al. 2008; Evans 1976; Losey and Denno 1998). Increasing size ratios between predator and prey can lead to the evolution of stronger antipredator response (Evans 1976; Binz et al. 2014). H. axyridis and C. septempunctata are relatively large, however smaller native species elicited similar dropping rates in pea aphids, indicating that further cues or species traits could induce aphid dropping. Here, a relatively large, moving object can be considered as a general predator cue (Dill 1974; Sih 1986; Sih et al. 2010), initiating aphid dropping. In addition, higher activity of a predator can result in higher dropping rates of $A$. pisum, due to increased vibration or more potential aphid encounters (Francke et al. 2008). Furthermore, aphids attacked by a predator, can release an alarm pheromone (Bowers et al. 1972; Kislow and Edwards 1972; Nault et al. 1973), which can lead to dropping behavior of surrounding aphids (Roitberg and Myers 1978; Dill et al. 1990). In summary, we suggest that cues eliciting dropping behavior in pea aphids are 
general predator cues, which $H$. axyridis and native species have in common.

While dropping is a response to immediate predation risk, avoidance behavior towards chemical cues left by predators are a proxy for future predation risk. Aphids can leave the current host plant and move to neighboring host plants, due to e.g. predator disturbance (Roitberg et al. 1979) or water stress (Honěk et al. 1998). Since younger instars are limited in movement capacities, adults and older instars preferably walk away and look for neighboring host plants (Roitberg et al. 1979; Honěk et al. 1998). Consequently, adult and forth instar aphids, used in the cue avoidance experiments were able to choose between plants and were not impaired in movement activity, due to the developmental stage. We expected that aphids are more likely to respond to chemical cues of coevolved native predators and show a lack of recognition towards the chemical cues of the invasive predator. Aphids showed no avoidance to $H$. axyridis and three native lady beetle species (A. bipunctata, $H$. variegata and $P$. quatuordecimpunctata), but against C. septempunctata cues. This finding is consistent with the results of Ninkovic et al. (2013), who showed that C. septempunctata cues repelled cherry oat aphids Rhopalosiphum padi Linnaeus (Hemiptera: Aphididae) from barley plants Hordeum vulgare Linnaeus (Poales: Poaceae). Thus, aphids can detect chemical traces of coccinellid predators and subsequently avoid feeding sites (Ninkovic et al. 2013). Predation risk can further induce the production of winged aphid offspring, accounting for the survival of the next generation on new plants (Dixon and Agarwala 1999). Chemical cues of lady beetles consist of numerous chemical compounds (Hemptinne et al. 1998; Hemptinne and Dixon 2000). Although the composition of chemical cues are species specific, certain compounds can appear across species (Magro et al. 2010). Native and non-native lady beetle species, bearing similar cues, could induce comparable prey avoidance. Thus, cue similarity between species should be considered, when testing for cue recognition. Magro et al. (2010) found that chemical cue composition of invasive $H$. axyridis larvae differed significantly from those of native $A$. bipunctata and $C$. septempunctata cues, whereas cue compositions of the two native species showed higher similarities. Since avoidance was only observed in treatment plants bearing $C$. septempunctata cues, our results indicate that species specific cues are involved (Sih et al. 2010). However, the chemical compounds in adult $C$. septempunctata cues that induce aphid avoidance are not identified and it remains unknown, if they are part of the chemical profile of the other lady beetle species. Contrary to our hypothesis, A. pisum did not avoid cues of the smaller native species. We suggest that larger predators exert stronger selection pressure on prey (see Binz et al. 2014). Antipredator responses are associated with costs and therefore depend on the degree of risk perceived by the prey (Kats and Dill 1998; Carthey and Banks 2014). According to our results, $C$. septempunctata is the most voracious predator among the tested native species, possibly inducing cue avoidance as an evolutionary response of A. pisum to avoid severe future predation risk. Our results further indicate that, cues of the equally voracious $H$. axyridis did not repell A. pisum, suggesting that $A$. pisum could not evolve adequate predator recognition, due to a shorter coevolutionary time with $H$. axyridis.

\section{Conclusion}

We suggest, that $H$. axyridis has a competition advantage when preying on pea aphids compared to smaller native species, due to predator size rather than due to missing predator recognition. Immediate risk by the presence of a predator elicits dropping behavior in A. pisum, regardless of the origin of the lady beetle species. However, A. pisum responds only to chemical cues of the native $C$. septempunctata. A higher selection pressure of larger predators on A. pisum, might explain the missing cue avoidance towards the three smaller native species, whereas predator-naïveté might be the cause for missing chemical cue recognition of the large, invasive $H$. axyridis. Although $H$. axyridis and $C$. septempunctata consumed similar numbers of aphids in our laboratory experiment, lower aphid predation rate of $C$. septempunctata might be expected under natural conditions, due to stronger cue avoidance of A. pisum. Our results indicate that size differences with native predators as well as missing cue avoidance can contribute to the invasion potential of non-native species.

Acknowledgements Open Access funding provided by Projekt DEAL. We thank Laura M. Japke, Carolin Gutwirth, 
Jette Diekmann and Denise Bertleff for help with the insect maintenance and collecting. We are grateful to the Julius KühnInstitut (Braunschweig, Germany) for providing pea aphids. Thanks to John J. Obrycki and two anonymous reviewers for their valuable comments on earlier versions of the manuscript. The study was funded by the Deutsche Forschungsgemeinschaft (DFG) under grant number BU3382/1-1 to RB.

Funding This study was funded by the Deutsche Forschungsgemeinschaft (DFG) under grant number BU3382/ 1-1 to RB.

\section{Compliance with ethical standards}

Conflict of interest The authors declare that they have no conflict of interest.

Human and animal rights All applicable international, national, and/or institutional guidelines for the care and use of animals were followed.

Open Access This article is licensed under a Creative Commons Attribution 4.0 International License, which permits use, sharing, adaptation, distribution and reproduction in any medium or format, as long as you give appropriate credit to the original author(s) and the source, provide a link to the Creative Commons licence, and indicate if changes were made. The images or other third party material in this article are included in the article's Creative Commons licence, unless indicated otherwise in a credit line to the material. If material is not included in the article's Creative Commons licence and your intended use is not permitted by statutory regulation or exceeds the permitted use, you will need to obtain permission directly from the copyright holder. To view a copy of this licence, visit http://creativecommons.org/licenses/by/4.0/.

\section{References}

Alyokhin A, Sewell G (2004) Changes in a lady beetle community following the establishment of three alien species. Biol Invasions 6:463-471

Bates D, Maechler M, Bolker B, Walker S (2015) Fitting linear mixed-effects models using lme4. J Stat Softw 67:1-48

Binz H, Bucher R, Entling MH, Menzel F (2014) Knowing the risk: crickets distinguish between spider predators of different size and commonness. Ethology 120:99-110

Blossey B, Notzold R (1995) Evolution of increased competitive ability in invasive nonindigenous plants: a hypothesis. J Ecol 83:887-889

Bowers WS, Nault LR, Webb RE, Dutky SR (1972) Aphid alarm pheromone: isolation, identification, synthesis. Science 177:1121-1122

Brose U, Ehnes RB, Rall BC, Vucic-Pestic O, Berlow EL, Scheu $S$ (2008) Foraging theory predicts predator-prey energy fluxes. J Anim Ecol 77:1072-1078

Brown MW, Miller SS (1998) Coccinellidae (Coleoptera) in apple orchards of eastern West Virginia and the impact of invasion by Harmonia axyridis. Entomological News 109:143-151

Brown PMJ, Adriaens T, Bathon H, Cuppen J, Goldarazena A, Hagg T, Kenis M, Klausnitzer BEM, Kovar I, Loomans AJM, Majerus MEN, Nedved O, Pedersen J, Rabitsch W, Roy HE, Ternois V, Zakharov IA, Roy DB (2008) Harmonia axyridis in Europe: spread and distribution of a nonnative coccinellid. Biocontrol 53:5-21

Bucher R, Binz H, Menzel F, Entling MH (2014) Effects of spider chemotactile cues on arthropod behavior. J Insect Behav 27:567-580

Bucher R, Menzel F, Entling MH (2015a) Risk of spider predation alters food web structure and reduces local herbivory in the field. Oecologia 178:571-577

Bucher R, Heinrich H, Entling MH (2015b) Plant choice, herbivory and weight gain of wood crickets under the risk of predation. Entomol Exp Appl 155:148-153

Carthey AJ, Banks PB (2014) Naïveté in novel ecological interactions: lessons from theory and experimental evidence. Biol Rev 89:932-949

Cox JG, Lima SL (2006) Naiveté and an aquatic-terrestrial dichotomy in the effects of introduced predators. Trends Ecol Evol 21:674-680

Dill LM (1974) The escape response of the zebra danio (Brachydanio rerio). I. The stimulus for escape. Anim Behav 22:711-722

Dill LM, Fraser AH, Roitberg BD (1990) The economics of escape behaviour in the pea aphid, Acyrthosiphon pisum. Oecologia 83:473-478

Dixon AFG (2000) Insect predator-prey dynamics: ladybird beetles and biological control. Cambridge University Press, Cambridge

Dixon AFG, Agarwala BK (1999) Ladybird-induced life-history changes in aphids. Proc R Soc Lond B Biol Sci 266:1549-1553

Eberhard WG (1982) Beetle horn dimorphism: making the best of a bad lot. Am Nat 119:420-426

Evans HF (1976) The role of predator-prey size ratio in determining the efficiency of capture by Anthocoris nemorum and the escape reactions of its prey, Acyrthosiphon pisum. Ecol Entomol 1:85-90

Finlayson C, Alyokhin A, Gross S, Porter E (2010) Differential consumption of four aphid species by four lady beetle species. J Insect Sci 10:1-10

Fox J, Weisberg S (2019) An R companion to applied regression, 3rd edn. Sage, Thousand Oaks

Francke DL, Harmon JP, Harvey CT, Ives AR (2008) Pea aphid dropping behavior diminishes foraging efficiency of a predatory ladybeetle. Entomol Exp Appl 127:118-124

Gordon RD (1985) The Coccinellidae (Coleoptera) of America north of Mexico. J N Y Entomol Soc 93:1-912

Hemptinne JL, Dixon AF (2000) Defence, oviposition and sex: semiochemical parsimony in two species of ladybird beetles (Coleoptera: Coccinellidae)? a short review. Eur J Entomol 97:443-448

Hemptinne JL, Lognay G, Dixon AFG (1998) Mate recognition in the two-spot ladybird beetle, Adalia bipunctata: role of chemical and behavioural cues. J Insect Physiol 44:1163-1171

Hodek I (1973) Biology of Coccinellidae. Academia, Prague 
Hoki E, Losey J, Ugine TA (2014) Comparing the consumptive and non-consumptive effects of a native and introduced lady beetle on pea aphids (Acyrthosiphon pisum). Biol Control 70:78-84

Honěk A, Jarošík V, Lapchin L, Rabasse JM (1998) The effect of parasitism by Aphelinus abdominalis and drought on the walking movement of aphids. Entomol Exp Appl 87:191-200

Hothorn T, Bretz F, Westfall P (2008) Simultaneous inference in general parametric models. Biometrical J 50:346-363

Hufbauer RA, Torchin ME (2007) Integrating ecological and evolutionary theory of biological invasions. In: Nentwig W (ed) Biological invasions. Springer, Berlin, pp 79-96

Hukusima S, Ohwaki T (1972) Further notes on feeding biology of Harmonia axyridis Pallas (Coleoptera: Coccinellidae). Res Bull Fac Agric Gifu Univ 33:75-82

Kats LB, Dill LM (1998) The scent of death: chemosensory assessment of predation risk by prey animals. Ecoscience 5:361-394

Kislow CJ, Edwards LJ (1972) Repellent odour in aphids. Nature 235:108-109

Klausnitzer B (2002) Harmonia axyridis (Pallas, 1773) in Deutschland (Col., Coccinellidae). Entomologische Nachrichten und Berichte 46:177-183

Labrie G, Coderre D, Lucas E (2008) Overwintering strategy of multicolored Asian lady beetle (Coleoptera: Coccinellidae): cold-free space as a factor of invasive success. Ann Entomol Soc Am 101:860-866

Lang C, Menzel F (2011) Lasius niger ants discriminate aphids based on their cuticular hydrocarbons. Anim Behav 82:1245-1254

Lees AD (1966) The control of polymorphism in aphids. Adva Insect Physiol 3:207-277

Lima SL, Dill LM (1990) Behavioral decisions made under the risk of predation: a review and prospectus. Can J Zool 68:619-640

Losey JE, Denno RF (1998) The escape response of pea aphids to foliar-foraging predators: factors affecting dropping behaviour. Ecol Entomol 23:53-61

Magro A, Ducamp C, Ramon-Portugal F, Lecompte E, CrouauRoy B, Dixon AFG, Hemptinne JL (2010) Oviposition deterring infochemicals in ladybirds: the role of phylogeny. Evol Ecol 24:251-271

Majerus M, Strawson V, Roy H (2006) The potential impacts of the arrival of the harlequin ladybird, Harmonia axyridis (Pallas) (Coleoptera: Coccinellidae), in Britain. Ecol Entomol 31:207-215

Mestre L, Bucher R, Entling MH (2014) Trait-mediated effects between predators: ant chemical cues induce spider dispersal. J Zool 293:119-125

Mishra G, Kumar B, Shahid M, Singh D, Omkar (2011) Evaluation of four co-occurring ladybirds for use as biocontrol agents of the pea aphid, Acyrthosiphon pisum (Homoptera: Aphididae). Biocontrol Sci Tech 21:991-997

Nault LR, Edwards LJ, Styer WE (1973) Aphid alarm pheromones: secretion and reception. Environ Entomol 2:101-105

Ninkovic V, Feng Y, Olsson U, Pettersson J (2013) Ladybird footprints induce aphid avoidance behavior. Biol Control 65:63-71
Obrycki JJ, Kring TJ (1998) Predaceous Coccinellidae in biological control. Annu Rev Entomol 43:295-321

Obrycki JJ, Giles KL, Ormord AM (1998) Interactions between an introduced and indigenous coccinellid species at different prey densities. Oecologia 117:279-285

Pasteels JM (2007) Chemical defence, offence and alliance in ants-aphids-ladybirds relationships. Popul Ecol 49:5-14

Peccoud J, Simon JC (2010) The pea aphid complex as a model of ecological speciation. Ecol Entomol 35:119-130

Peccoud J, Ollivier A, Plantegenest M, Simon JC (2009) A continuum of genetic divergence from sympatric host races to species in the pea aphid complex. Proc Natl Acad Sci 106:7495-7500

R Development Core Team (2017) R: a language and environment for statistical computing. R Foundation for Statistical Computing, Vienna, Austria. https://www.R-project.org/

Roitberg BD, Myers JH (1978) Adaptation of alarm pheromone responses of the pea aphid Acyrthosiphon pisum (Harris). Can J Zool 56:103-108

Roitberg BD, Myers JH, Frazer BD (1979) The influence of predators on the movement of apterous pea aphids between plants. J Anim Ecol 48:111-122

Roy HE, Adriaens T, Isaac NJB, Kenis M, Onkelinx T, San MG, Brown PMJ, Hautier L, Poland R, Roy DB, Comont R, Eschen R, Frost R, Zindel R, van Vlaenderen J, Nedvěd O, Ravn HP, Grégoire J-C, de Biseau J-C, Maes D (2012) Invasive alien predator causes rapid declines of native European ladybirds. Divers Distrib 18:717-725

Ruan CC, Du WM, Wang XM, Zhang JJ, Zang LS (2012) Effect of long-term cold storage on the fitness of pre-wintering Harmonia axyridis (Pallas). Biocontrol 57:95-102

Sih A (1986) Antipredator responses and the perception of danger by mosquito larvae. Ecology 67:434-441

Sih A, Bolnick DI, Luttbeg B, Orrock JL, Peacor SD, Pintor LM, Preisser E, Rehage JS, Vonesh JR (2010) Predator-prey naïveté, antipredator behavior, and the ecology of predator invasions. Oikos 119:610-621

Thomas C (1878) A list of the species of the tribe Aphidini, family Aphidae, found in the UnitedStates, which have been heretofore named, with descriptions of some new species. Bull Ill State Lab Nat Hist 2:3-16

Van Lenteren JC, Loomans AJ, Babendreier D, Bigler F (2008) Harmonia axyridis: an environmental risk assessment for Northwest Europe. Biocontrol 53:37-54

Villagra CA, Ramirez CC, Niemeyer HM (2002) Antipredator responses of aphids to parasitoids change as a function of aphid physiological state. Anim Behav 64:677-683

Watanabe M (2002) Cold tolerance and myo-inositol accumulation in overwintering adults of a lady beetle, Harmonia axyridis (Coleoptera: Coccinellidae). Eur J Entomol 99:5-9

Weisser WW, Braendle C, Minoretti N (1999) Predator-induced morphological shift in the pea aphid. Proc R Soc Lond B 266:1175-1181

Publisher's Note Springer Nature remains neutral with regard to jurisdictional claims in published maps and institutional affiliations. 